\title{
Análise de Discurso e de Conteúdo de uma Formação em Pensamento Computacional para Professores
}

\section{Taiser T. T. Barros ${ }^{1,2}$, Eliseo Berni Reategui ${ }^{1}$, Ricardo Radaelli Meira ${ }^{3}$, Adriano Canabarro Teixeira ${ }^{4}$}

\author{
${ }^{1}$ PPGIE - Programa de Pós-Graduação em Informática na Educação \\ Universidade Federal do Rio Grande do Sul (UFRGS)
}

\author{
${ }^{2}$ Serviço Nacional de Aprendizagem Industrial do Rio Grande do Sul - SENAI RS \\ ${ }^{3}$ Instituto Federal Farroupilha Unidade Cruz Alta - Cruz Alta, RS - Brazil \\ ${ }^{4}$ PPG em Educação/PPGEdu Universidade de Passo Fundo - Passo Fundo, RS - Brazil \\ \{tttbarros78, eliseoreategui,ricardoradaelli\}@gmail.com, teixeira@upf.br
}

\begin{abstract}
This paper describes a process of teacher training that brought concepts related to Computational Thinking using Scratch. Teachers' impressions regarding training were analyzed through content and discourse analysis with coding process.
\end{abstract}

Resumo. Este trabalho descreve um processo de formação de professores que trouxe conceitos relacionados ao Pensamento Computacional utilizando o Scratch. As impressões dos professores com relação à formação foram analisadas através das análises de conteúdo e de discurso com processo de codificação.

\section{Introdução}

O desenvolvimento de atividades do Pensamento Computacional (PC) em sala de aula é uma realidade em diversos países e instituições assim como apresentado por uma série de autores, dentre eles [Miotto and Cardoso 2014, de Lima Oliveira 2009, Brackmann 2017, Morais et al. 2017], com trabalhos que investigam por exemplo a perspectiva do aluno, relatando como estes encaram o uso de novas tecnologias, ou, dos professores que estão sendo formados para agirem como mediadores no uso destas tecnologias. As áreas de formação da informática e Matemática foram as que se apresentaram em maior número na literatura pesquisada, uma vez que estas áreas possuem relação direta com o PC.

Um item em destaque quanto à formação de professores no contexto do PC são os relatos da resistência de alguns ao uso de tecnologias, seja na utilização do computador ou na disponibilidade de aprender sobre uma linguagem de programação ou até mesmo outros tópicos relacionados à informática. Assim, neste trabalho buscou-se analisar a impressão dos professores frente a uma formação em PC, analisando o discurso (quando necessário captar o que vai além do que foi dito ou escrito [Orlandi 2009]) e conteúdo de suas falas que foram transcritas e codificadas, sendo o processo de codificação utilizado proposto em [Saldana 2009].

\section{Aspectos do PC e a formação de Professores}

O PC pode ser compreendido de forma a utilizar o computador não como simples equipamento de edição de textos ou de acesso à World Wide Web, mas como ferramenta que 
VII Congresso Brasileiro de Informática na Educação (CBIE 2018)

Anais do XXIX Simpósio Brasileiro de Informática na Educação (SBIE 2018)

auxilia na resolução de problemas. O PC pode ser definido como [Wing 2006]: "Conjunto de atitudes e habilidades universalmente aplicáveis, que todos, não apenas cientistas da computação, deveriam estar ansiosos para aprender e usar". Sua introdução desde as séries iniciais até o ensino médio e graduação é uma necessidade [Weintrop et al. 2016] nas disciplinas de Matemática e Ciências visto a crescente incorporação de aspectos computacionais nestas áreas. Uma ferramenta que pode auxiliar nesta tarefa é o Scratch, criado pelo grupo Lifelong Kindergarten do Massachusetts Institute of Technology (MIT).

A maior parte da formação em PC para professores [Imberman et al. 2014] concentra-se em incentivar a incorporação não só no currículo da ciência da computação mas também na Matemática. No Brasil [Valente 2016] a formação dos professores é um grande desafio pois não há consenso das áreas da tecnologia na educação e da ciência da computação sobre em que consiste o PC, e assim, é difícil estipular como abordar o tema na educação e consequentemente formar educadores no assunto.

\section{Metodologia}

Esta pesquisa foi delineada como um estudo de caso de caráter descritivo e análise quantiqualitativa. O grupo participante consistiu de 53 professores do ensino fundamental (13 de Informática e 40 de Matemática) de um município do Rio Grande do Sul. Os encontros presenciais ocorreram em um Centro de Formação Profissional do SENAI que disponibilizou um laboratório de informática, sendo realizados 4 encontros entre Setembro de 2017 e Maio de 2018. Os professores foram entrevistados e suas falas foram gravadas, transcritas e posteriormente codificadas. Os códigos foram criados por dois codificadores separadamente com o nível de concordância verificado com a ferramenta http://dfreelon.org/utils/recalfront/recal2/ que calcula o coeficiente de Cohen's Kappa classificando os níveis de concordância de "Pequeno" (0.00) a "Quase Perfeito" (1.00) [Stemler 2001].

A primeira análise de concordância apresentou $28.13 \%$ dos valores de coeficiente com classificação acima de "Moderado" (0.41 - 0.60) e após o processo de conciliação proposto por [Garrison et al. 2006] a totalidade da codificação atingiu classificação igual ou superior a "Significativa". O número de ocorrências de cada código criado (após entrevista e transcrição das falas dos professores) é apresentado na figura 1 e a descrição dos mesmos é apresentada na tabela 1.

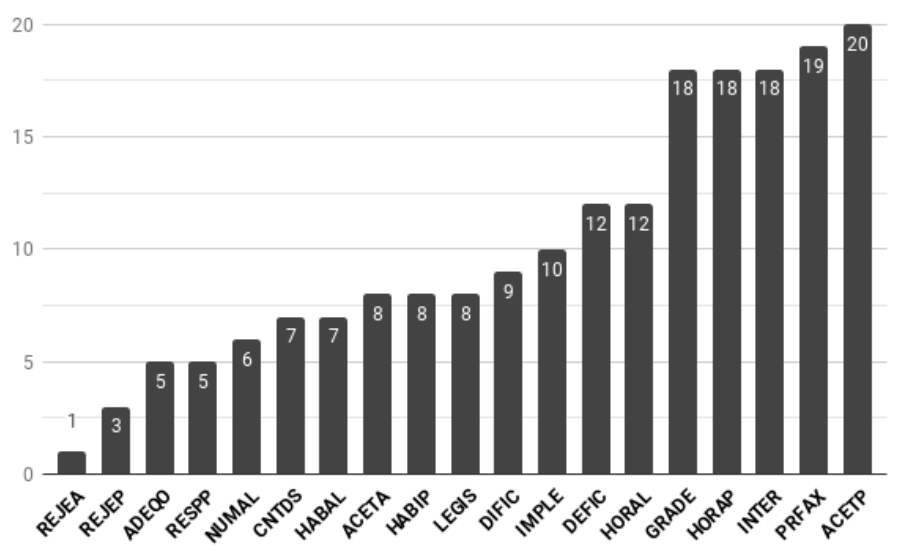

Figura 1. Quantidade de Ocorrências dos Códigos. 
VII Congresso Brasileiro de Informática na Educação (CBIE 2018)

Anais do XXIX Simpósio Brasileiro de Informática na Educação (SBIE 2018)

Tabela 1. Descrição dos códigos.

\begin{tabular}{l|l}
\hline Código & Descrição \\
\hline GRADE & Grade curricular a escola e/ou currículo implementado. \\
CNTDS & Para cumprir conteúdos obrigatórios, não há tempo disponível para trabalhar o Scratch. \\
LEGIS & Falta documentação/legislação que oriente a implementação da informática nas escolas. \\
HABAL & Habilidade dos alunos no contexto da informática: facilidade de programar, lógica, etc. \\
HABIP & Professor referenciou precisar de habilidades no Scratch para aplicar com os alunos. \\
DIFIC & Comentários dos professores sobre sua dificuldade com relação à informática. \\
INTER & Qualquer referência à interdisciplinaridade. \\
IMPLE & Como implementar o Scratch: jogos, projetos, oficina, etc. \\
ACETA & Aceitação dos alunos com relação ao Scratch. \\
ACETP & Aceitação dos professores com relação ao Scratch. \\
REJEA & Rejeição dos alunos com relação ao Scratch. \\
REJEP & Rejeção dos professores com relação ao Scratch. \\
RESPP & Professor reconhece que deve estudar para compreender como utilizar o Scratch. \\
PRFAX & Necessidade de um profissional que auxilie com questões de informática na escola. \\
ADEQO & Infraestrutura da escola está adequada para desenvolvimento de atividades. \\
DEFIC & Infraestrutura da escola não está adequada para desenvolvimento de atividades. \\
HORAP & Carga horária disponível dos professores para trabalhar com informática. \\
HORAL & Horários disponíveis para utilizar os laboratórios de informática da escola. \\
NUMAL & Referência ao número de alunos em uma turma. \\
\hline
\end{tabular}

\section{Análise e Discussão dos Resultados}

O número de ocorrências de cada código traz uma série de informações sobre o discurso dos professores, como as 20 ocorrências do código ACETP (70\% Matemática) que indica boa aceitação do Scratch ao mesmo tempo que 19 ocorrências de PRFAX (79\% Matemática) demonstram que os professores de Matemática não estão dispostos a assumir o recurso sem "dependerem" do auxílio de um professor de informática, sendo este um comportamento característico [de Lima Oliveira 2009] pois professores menos ambientados com tecnologia apresentam menor interesse e disponibilidade em aprender sozinhos.

Para verificar se problemas de infraestrutura poderiam afetar a aceitação à formação, relacionou-se o número de ocorrências de REJEP com DEFIC, com somente 1 ocorrência, o que revela que este item não é considerado um problema. Porém mesmo com infraestrutura adequada existe resistência à formação, o que permite uma analogia com [Ma et al. 2005] onde somente a disponibilidade de infraestrutura de informática não é item suficiente para garantir que o computador seja adotado como ferramenta.

A resistência ao Scratch e intrinsicamente à formação por parte dos professores de Matemática é problemática considerando-se o texto da Base Nacional Comum Curricular $(\mathrm{BNCC})^{1}$ onde das 4 ocorrências do termo PC, todas estão dentro da seção "4.2. A ÁREA DE MATEMÁTICA", ou seja, espera-se uma relação direta da Matemática com o PC. Ideia esta encontrada similarmente em trabalhos como o de [Brackmann 2017, p. 163164] que traz a seguinte consideração:

“... deve ocorrer uma formação de professores para que atuem como

${ }^{1}$ Disponível em http: / /basenacionalcomum.mec.gov.br/, acesso em 12/06/2018. 
VII Congresso Brasileiro de Informática na Educação (CBIE 2018)

Anais do XXIX Simpósio Brasileiro de Informática na Educação (SBIE 2018)

multiplicadores do saber ... Certos países, como os Estados Unidos da América e a Alemanha, encontraram a solução quanto à falta de professores para lecionar a disciplina de Computação nas aulas de Matemática, podendo esse exemplo servir de modelo ao Brasil."

Ainda, o comportamento de resistência à informática detectado é análogo ao que foi relatado por [Penteado et al. 2000, p. 11]:

\footnotetext{
"O contato com professores através de pesquisas e cursos desenvolvidos ... mostra que grande parte deles ainda conhece pouco de informática e não se sente em condições de incorporar as Tecnologias Informáticas em sua prática. Alguns tendem a encarar com desconfiança e resistência a introdução das novas tecnologias de informação e comunicação."
}

E conforme a consideração de [Leite et al. 2017], há a possibilidade da resistência dos professores ao uso da tecnologia estar fundamentada no paradigma dos currículos tradicionalistas.

\section{Conclusões}

Este trabalho apresentou uma proposta de formação de professores no contexto do PC, onde as análises de conteúdo e de discurso juntamente com a codificação permitiram avaliar as impressões dos professores com relação à formação proposta.

Observou-se que existe certa resistência dos professores, principalmente do grupo da Matemática, em aceitar o PC como ferramenta de sala de aula, sendo este resultado similar ao encontrados em [Penteado et al. 2000] há 18 anos, mostrando que o processo de aceitação da tecnologia pode ser lento em relação ao avanço da mesma.

Ainda, a constatação sobre a resistência à tecnologia por parte dos professores é problemática uma vez que o apoio dos mesmos é fundamental para que se possa disseminar os conceitos do PC juntos aos alunos. Em contrapartida pode-se encarar esta resistência, como um campo amplo para o desenvolvimento de propostas de pesquisa com o intuito de disseminar para um número cada vez maior de professores os benefícios da utilização da tecnologia em sala de aula contribuindo para sua atividade docente.

Como trabalhos futuros, pretende-se realizar visitas nas escolas onde os professores participantes da pesquisa atuam, verificando quais as condições de trabalho e infraestrutura que estes possuem, buscando estratégias que aumentem a aceitação dos mesmos à utilização do PC e implementando junto aos alunos parte dos conceitos discutidos na formação.

\section{Agradecimentos}

Os autores agradecem ao SENAI-RS pela disponibilização do espaço para implementação da formação e a todos os professores e equipe pedagógica envolvidos na pesquisa. 
VII Congresso Brasileiro de Informática na Educação (CBIE 2018)

Anais do XXIX Simpósio Brasileiro de Informática na Educação (SBIE 2018)

\section{Referências}

Brackmann, C. P. (2017). Desenvolvimento do Pensamento Computacional Através de Atividades Desplugadas na Educação Básica. PhD thesis, Universidade Federal do Rio Grande do Sul (UFRGS), Porto Alegre - RS.

de Lima Oliveira, E. C. (2009). O uso do scratch no ensino fundamental: possibilidades de incorporação curricular segundo professoras dos anos iniciais. Master's thesis, Pontifícia Universidade Católica de Minas Gerais, Belo Horizonte.

Garrison, D., Cleveland-Innes, M., Koole, M., and Kappelman, J. (2006). Revisiting methodological issues in transcript analysis: Negotiated coding and reliability. The Internet and Higher Education, 9(1):1-8.

Imberman, S., Sturm, D., and Q. Azhar, M. (2014). Computational thinking: expanding the toolkit. 29:39-46.

Leite, M., Reinaldo, F., Maschio, E., Marczal, D., and Moreira, C. (2017). Pensamento computacional nas escolas: Limitado pela tecnologia, infraestrutura ou prática docente? In Anais dos Workshops do VI Congresso Brasileiro de Informática na Educação (CBIE 2017), pages 1002-1010. SBC - Sociedade Brasileira de Computação.

Ma, W. W.-k., Andersson, R., and Streith, K.-O. (2005). Examining user acceptance of computer technology: an empirical study of student teachers. Journal of Computer Assisted Learning, 21(6):387-395.

Miotto, P. and Cardoso, V. C. (2014). A utilização do software scratch para o ensino e a aprendizagem do conceito de função. Os Desafios da Escola Pública Paranaense na Perspectiva do Professor PDE, I.

Morais, A. D. d., Basso, M. V. d. A., and Fagundes, L. A. d. C. (2017). Educação Matemática Ciência da Computação na escola: aprender a programar fomenta a aprendizagem de matemática? Ciência Educação (Bauru), 23:455 - 473.

Orlandi, E. P. (2009). Análise de Discurso - Princípios e Procedimentos. Editora Pontes, Campinas, $8^{\mathrm{a}}$ edition.

Penteado, M., Borba, M., da Silva, H., and Gracias, T. (2000). A informática em ação: formação de professores, pesquisa e extensão. Olho d'Água, São Paulo, SP, $1^{\text {a }}$ edition.

Saldana, J. (2009). The Coding Manual for Qualitative Researchers. SAGE Publications.

Stemler, S. (2001). An overview of content analysis. Practical Assessment, Research \& Evaluation, 7(17).

Valente, J. (2016). Integração do pensamento computacional no currículo da educação básica: diferentes estratégias usadas e questões de formação de professores e avaliação do aluno. Revista e-Curriculum, 14(3):864-897.

Weintrop, D., Beheshti, E., Horn, M., Orton, K., Jona, K., Trouille, L., and Wilensky, U. (2016). Defining computational thinking for mathematics and science classrooms. Journal of Science Education and Technology, 25(1):127-147.

Wing, J. M. (2006). Computational thinking. Commun. ACM, 49(3):33-35. 